\title{
Interaksi Simbolik dalam Kegiatan After Sales di Dealer Nissan (Studi Kasus PT. Wahana Wirawan)
}

\author{
Alanwari Bulan Putra, Muhammad Adi Pribadi \\ Alanwaribp36@gmail.com,Adip@fikom.untar.ac.id \\ Fakultas Ilmu Komunikasi Universitas Tarumanagara
}

\begin{abstract}
Symbolic interactions are interactions with others where communication and participation play a very important role. Symbolic interaction theory focuses on the importance of selfconcepts and perceptions of individuals based on interactions with other individuals. Symbolic interactionism plays an important role in After Sales activities. After sales is one of the activities to satisfy customers on a product. The purpose of After Sales Activities at PT. Nissan Motor Indonesia aims to increase customer satisfaction and add Company Profit. After Sales plays a very important role in the automotive world, because After Sales can maintain good relations in the long run between the Company and Customers. After Sales is in the form of service, warranty and others. PT. Nissan Motor Indonesia is one of the automotive companies that have excellent After Sales. In carrying out activities After Sales Theory of symbolic interaction of mind, self, and society plays an important role. This study uses a qualitative methodology with the Case Study method. Data collection was done by in-depth interviews with a team from PT. Wahana Wirawan, participant observation, Documentation and archive record. The conclusion of this research is in conducting After Sales activities, PT. Nissan Motor Indonesia has 8 stages consisting of Proactive Contact Program (PCP), Appointment, Reception, Job Progress Control, Service Work, Quality Control, Vehicle Submission, and Follow Up. At this stage there is the Symbolic Interaction theory of Mind, Self, and Society. This After Sales activity or process is to increase Customer Satisfaction.
\end{abstract}

Keywords: after sales, case studies, symbolic interaction, customer satisfaction, qualitative

\begin{abstract}
Abstrak
Interaksi Simbolik adalah interaksi dengan orang lain dimana komunikasi dan partisipasi memegang peranan sangat penting. Teori interaksi simbolik berfokus kepada pentingnya konsep diri dan persepsi yang dimiliki individu berdasarkan interaksi dengan individu lainnya. Interaksi simbolik berperan penting dalam kegiatan After Sales. After sales adalah salah satu kegiatan untuk memuaskan pelanggan pada suatu produk. Tujuan Kegiatan After Sales pada PT. Nissan Motor Indonesia bertujuan untuk meningkatkan kepuasan pelanggan dan menambahkan profit perusahaan. After Sales berperan sangat penting di dalam dunia Otomotif, karena After Sales ini dapat menjaga hubungan baik dalam jangka panjang antara Perusahaan dengan Pelanggan. After Sales ini berupa pelayanan Service, Garansi, dan lainlain. PT. Nissan Motor Indonesia adalah salah satu perusahaan otomotif yang memiliki After Sales sangat baik. Dalam melakukan kegiatan After Sales Teori Interaksi simbolik mind, self, dan society berperan penting. Penelitian ini menggunakan metodologi kualitatif dengan metode Studi Kasus. Pengumpulan data dilakukan dengan wawancara mendalam dengan tim dari PT. Wahana Wirawan, Observasi partisipan, Dokumentasi, dan Rekaman Arsip. Kesimpulan dari penelitian ini adalah dalam melakukan kegiatan After Sales, PT. Nissan Motor Indonesia memiliki 8 tahapan yang terdiri dari Proactive Contact Program (PCP), Appointment, Penerimaan, Job Progress Control, Pekerjaan servis, Kontrol kualitas, Penyerahan kendaraan, dan Follow Up. Pada tahapan tersebut terdapat teori Interaksi Simbolik
\end{abstract}


dari Mind, Self, dan Society. Kegiatan atau proses After Sales ini untuk meningkatkan Kepuasan Pelanggan.

Kata Kunci: after sales, interaksi simbolik, kualitatif, kepuasan pelanggan, studi kasus

\section{Pendahuluan}

Fenomena persaingan antar produsen untuk mendapatkan banyak konsumen membuat setiap produsen menyadari suatu kebutuhan untuk memaksimalkan asetaset perusahaan demi kelangsungan perusahaan. Dalam hal tersebut maka setiap perusahaan otomotif berlomba-lomba untuk memberikan Standar Operation Procedures (SOP) di setiap Dealernya agar pelanggan merasa puas dengan pelayanan yang diberikan perusahaan.

Dalam lingkungan persaingan yang sangat kompetitif, hal yang utama yang harus diprioritaskan oleh perusahaan adalah kepuasan pelanggan, agar dapat tetap bertahan, bersaing dan menguasai pasar. Perusahaan harus mengetahui hal-hal apa yang dianggap penting dan menjadi harapan pelanggannya. Pemahaman terhadap suara pelanggan merupakan prasyarat peningkatan mutu dan produktivitas terus menerus dalam mencapai kepuasan total pelanggan.

Pada dasarnya, After Sales dari perusahaan otomotif adalah sebuah layanan yang diberikan pada konsumen setelah melakukan pembelian produk. Layanan ini bisa diwujudkan dalam beberapa produk, mulai dari pemberian garansi dalam kurun waktu tertentu, garansi tukar barang, pelayanan perbaikan oleh tim yang bisa datang ke rumah, hingga customer service.

PT. Wahana Wirawan adalah salah satu Dealer kendaraan mobil Nissan yang memberikan layanan After Sales. Proses layanan After Sales yang diberikan oleh PT. Nissan Motor Indonesia adalah PCP, Appointment, Penerimaan, Job Progress Control, Pekerjaan Service, Kontrol Kualitas, Penyerahan Kendaraan, dan Follow Up After Sales. Proses-proses After Sales terdapat peran teori Interaksi Simbolik Mind, Self, Dan Society. Tujuan dari penelitian ini adalah mengetahui peran interaksi simbolik yang terjadi pada kegiatan After Sales di Dealer Nissan. Selain itu rumusan masalah dalam penelitian ini adalah bagaimana peran interaksi simbolik dalam kegiatan After Sales di Dealer Nissan.

\section{Metode Penelitian}

Jenis penelitian yang digunakan dalam penelitian ini adalah penelitian yang sifatnya deskriptif, yaitu suatu penelitian yang bertujuan untuk menjelaskan fenomena-fenomena sosial yang sedang terjadi di dalam kehidupan masyarakat dan apa yang dialami oleh subjek penelitian. Pada penelitian kualitatif, peneliti berusaha memahami subjek dari kerangka berpikirnya sendiri. Dengan demikian yang terpenting adalah pengalaman, pendapat, perasaan, dan pengetahuan partisipan.

Menurut Nazir (2011) metode deskriptif adalah suatu metode dalam meneliti status kelompok manusia, suatu objek, suatu kondisi, suatu sistem pemikiran, ataupun suatu kelas peristiwa pada masa sekarang. Menurut Jalaludin Rakhmat dalam bukunya yang berjudul Metode Penelitian Komunikasi (2007), mengatakan bahwa metode penelitian deskriptif bertujuan untuk:

1. Mengumpulkan informasi aktual secara rinci yang melukiskan gejala yang ada. 
2. Mengidentifikasi masalah dan memeriksa kondisi atau praktek-praktek yang berlaku.

3. Membuat perbandingan dan evaluasi.

4. Menentukan apa yang dilakukan orang lain dalam menghadapi masalah yang ada dan belajar dari pengalaman mereka untuk menetapkan rencana dan keputusan pada waktu yang akan datang.

Metode yang digunakan adalah metode studi kasus sesuai dengan yang disampaikan oleh Yin (2013). Studi kasus digunakan sebagai suatu penjelasan komprehensif yang berkaitan dengan berbagai aspek seseorang, suatu kelompok, suatu organisasi, suatu program, atau suatu situasi kemasyarakatan yang diteliti, diupayakan dan ditelaah sedalam mungkin.

Berdasarkan pengertian diatas, maka dapat disimpulkan bahwa studi kasus adalah metode yang berupaya untuk mengetahui dan mendalami suatu fenomena dengan mengumpulkan data-data dan informasi. Dalam penelitian ini si penulis ingin mengetahui secara mendalam bagaimana strategi pemasaran yang dilakukan oleh After Sales untuk meningkatkan kepuasan pelanggan di PT. Nissan Motor Indonesia.

Objek penelitian adalah masalah atau tema yang akan akan diteliti dan fokus penelitian, yaitu apa yang menjadi sasaran penelitian. Objek penelitian ini adalah Peran interaksi simbolik yang dilakukan After Sales. Peneliti akan melakukan wawancara secara langsung kepada narasumber untuk mendapatkan jawaban dari rumusan masalah dalam penelitian dan untuk melengkapi data-data yang terkait dengan proses penelitian. Selain itu peneliti akan menggunakan dokumentasi dan rekaman arsip.

\section{Hasil Penemuan dan Diskusi}

Metode pengumpulan data kualitatif pada penelitian ini wawancara mendalam yang dimana peneliti mewawancarai seorang After Sales di PT. Nissan Motor Indonesia. Peneliti mewawancarai beberapa karyawan After Sales di PT. Nissan Motor Indonesia dan PT. Wahana wirawan (selaku Dealer Nissan). Peneliti mewawancarai Manager After Sales PT. Nissan Motor Indonesia, Kepala bengkel PT. Wahana wirawan Dealer Nissan-Datsun Pluit, CRO (Customer Relation Officer) PT. Wahana Wirawan Dealer Nissan-Datsun Pluit.

Tabel 1. Informan

\begin{tabular}{cccc}
\hline No & Nama Informan & Jabatan & Keterangan \\
\hline 1. & Budhy Suryanto & $\begin{array}{c}\text { Manager After Sales PT. Nissan Motor } \\
\text { Indonesia }\end{array}$ & Informan 1 \\
\hline 2. & Totok & $\begin{array}{c}\text { Kepala Bengkel Dealer Nissan Datsun } \\
\text { Pluit }\end{array}$ & Informan 2 \\
\hline 3. & Shinta & $\begin{array}{c}\text { Customer Relations } \text { Officer } \text { (CRO) } \\
\text { Dealer } \text { Nissan Datsun Pluit. }\end{array}$ & Infroman 3 \\
\hline
\end{tabular}

Sumber Dokumentasi Sendiri (2019) 
Pada saat wawancara peneliti menemukan tahapan-tahapan proses yang dilakukan oleh Dealer Nissan-Datsun Pluit.

Gambar 1. Tahapan Proses After Sales.

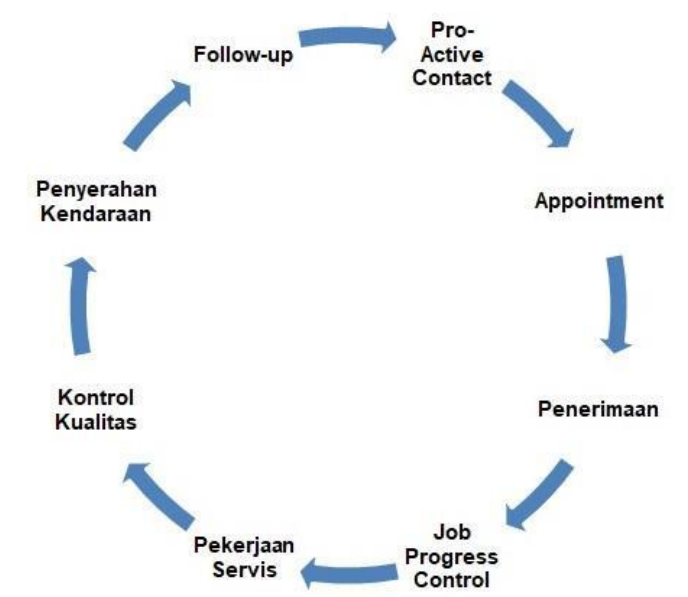

Sumber. Dokumentasi Penelitian (2019)

Pada gambar tersebut tahap pertama adalah Proactive Contact Program (PCP). PCP adalah PCP adalah program yang membantu mendorong pelanggan untuk datang mengunjungi Dealer yang bertujuan servis kendaraannya, dengan tetap berhubungan dengan setiap pelanggan selama periode kepemilikan kendaraan. PCP ini kegiatannya adalah service reminder service reminder ini adalah mengingatkan customer untuk datang ke bengkel melakukan service kendaraannya. Service reminder ini dilakukan dengan 2 cara : via SMS dan menelpon langsung pelanggan.

Tahap kedua adalah Appointment. Appointment dapat dibilang booking service jadi setelah di reminder oleh CRO atau PIC Pelanggan akan diarahkan untuk melakukan Appointment. Appointment ini sangat menguntungkan bagi Pelanggan dan juga Dealer salah satunya ketika Pelanggan datang pelanggan tidak perlu menunggu untuk servis. Ketika Appointment pelanggan didorong untuk membuat janji kepada Dealer untuk melakukan servis. Setiap harinya Appointment ada batasannya. Setiap $\mathrm{CRO}$ atau PIC harus menghitung jumlah Bay (tempat kerja) dan menghitung jumlah teknisi agar ketika Pelanggan yang sudah melakukan Appointment datang bengkel tidak penuh.

Tahap ketiga adalah penerimaan pelanggan. Penerimaan pelanggan oleh bengkel dimulai dari Pelanggan memasuki area bengkel sampai dengan kendaraannya selesai diperbaiki sangat mempengaruhi pandangan dan kesannya terhadap kualitas perbaikan yang dilakukan bengkel. Apakah bengkel tersebut benar-benar professional, sehingga kendaraannya dapat dikerjakan dengan benar. Pelayanan yang baik dan profesional dapat meningkatkan kepuasan dan loyalitas pelanggan terhadap bengkel. Saat penerimaan pelanggan ada beberapa langkah yang harus dilakukan oleh Service Advisor seperti, menyambut kedatangan pelanggan, penjelasan permasalahan pelanggan, penentuan Warranty / Garansi, Perkiraan biaya dan waktu perbaikan.

Tahap keempat adalah Job Progress Control. Job Progress Control ini bertujuan untuk mengalokasikan pekerjaan ke mekanik berdasarkan skill, pengetahuan dan pengalaman. Dengan alokasi pekerjaan diharapkan dapat meningkatkan efisiensi dan produktivitas bengkel. 
Tahap kelima Pekerjaan Service. Pekerjaan Service ini memiliki langkahlangkah yang harus diperhatikan seperti, Melakukan diagnosa untuk menemukan gejala kerusakan, memperoleh persetujuan dari pelanggan, memeriksa Spare Part, dan baru melakukan perbaikan.

Tahap keenam Kontrol kualitas. Tujuan Kontrol kualitas adalah menjamin semua kendaraan yang selesai diperbaiki dengan benar dan sesuai dengan keinginan pelanggan. Dengan adanya kontrol kualitas diharapkan dapat meningkatkan kesadaran mekanik dalam memperbaiki kendaraan pelanggan dengan benar dan meminimalkan perbaikan ulang.

Tahap ketujuh adalah penyerahan kendaraan. Penyerahan kendaraan dibagi menjadi dua, sebelum penyerahan kendaraan dan selama penyerahan kendaraan. Sebelum penyerahan kendaraan SA akan menelpon customer dan membuat janji untuk menyerahkan kendaraan. Penyerahan yang baik diawali dengan menyiapkan kendaraan tepat pada waktu yang dijanjikan. Hal ini berarti bahwa pelanggan telah siap untuk memeriksa tagihan, membayar tagihan dan membawa kendaraannya kembali. Selama penyerahan kendaraan SA harus memprioritaskan kepuasan pelanggan saat penyerahan kendaraan atas semua perbaikan yang dilakukan. Hal ini merupakan kunci untuk mempertahankan pelanggan yang setia.

Tahap terakhir adalah Follow Up. Setelah pelanggan melakukan servis di bengkel maka CRO (Customer Relation Officer) akan melakukan Follow Up dengan cara menelpon customer dan menanyakan bagaimana kendaraanya setelah di service lalu bagaimana pelayanan dari bengkel kami dari mula SA, Mekanik, Formen dan lainlain.

Dalam Proses-proses tersebut Teori Interaksi Simbolik sangat berperan. Pada saat melakukan PCP maka Society berperan. Menurut Joel M Charon dalam Pribadi, Suganda, Venus, dan Susanto (2018) Society terbentuk karena setiap individu yang ada di dalamnya sepakat untuk melaksanakan nilai dan aturan yang telah disepakati bersama. Nilai dan aturan disebut sebagai Generalized Other. Teori self berperan pada saat penerimaan tamu, ketika customer menyampaikan masalah terhadap kendaraannya, pada saat melakukan Follow Up. Saat SA menerima pelanggan maka Mind akan tercipta yang dimana SA akan memberikan simbol-simbol yang dapat dimengerti oleh Pelanggan seperti Salam dan sapa. Proses-proses After Sales berkaitan dengan Interaksi Simbolik.

\section{Kesimpulan}

Teori Interaksi simbolik Mind, Self, dan Society sangat berperan dalam proses After Sales. After Sales berisi mengenai Servis, garansi, dan SparePart terdapat peranperan interaksi simbolik yang sangat melekat. Pada tahapan-tahapan After Sales dari mulai PCP, Appointment, penerimaan, job progress control, pekerjaan servis, kontrol kualitas, penyerahan kendaraan, dan Follow Up terdapat teori-teori dari Mind, Self, dan Society.

Tujuan dari After Sales ini adalah meningkatkan kepuasan pelanggan sehingga membuat pelanggan menjadi loyal terhadap Nissan. After Sales dapat meningkatkan unit entry (kendaraan yang service di Dealer) dan juga profit, selain itu dapat membangun hubungan baik dengan pelanggan sehingga bisa menjaga pelanggan agar tetap memilih brand Nissan. After sales juga bisa menjadi media antara perusahaan dengan konsumen untuk bertukar informasi. Konsumen yang bertanya, komplain, atau mengklaim kerusakan akan menjadi masukan bagi perusahaan untuk mengetahui 
kekurangan produk mereka. Artinya, perusahaan bisa melakukan perbaikan kualitas produk yang mereka buat.

After Sales sangat penting dalam setiap brand Otomotif, Karena setiap pelanggan sebelum membeli suatu brand pasti memikirkan masalah servis, garansi, Spare Part. Sehingga dapat dikatakan bahwa After Sales ini bisa menjadi Before Sales atau sebelum pembelian Produk, Karena After Sales yang baik akan menarik pelanggan untuk membeli Brand Nissan.

\section{Ucapan Terima Kasih}

Penulis mengucapkan rasa syukur dan terima kasih atas penyelesaian penelitian ini kepada Fakultas Ilmu Komunikasi Universitas Tarumanagara dan para narasumber dan responden yang menjadi populasi penelitian yang sudah bersedia meluangkan waktunya serta semua pihak.

\section{Daftar Pustaka}

Budhy Suryanto. (2019, November 28). Wawancara pribadi.

J.D. Power. CSI (Customer Satisfaction Index). September 23, 2019. https://japan.jdpower.com/press-releases/jd-power-2019-indonesia-customerservice-index-mass-market-study-bahasa.

Nazir, Moh. (2011). Metode Penelitian. Bogor: Ghalia Indonesia.

$\begin{array}{lllll}\text { Nissan. } & \text { (n.d). Tentang Nissan. September }\end{array}$ https://www.nissan.co.id/artikel.html

Pribadi, Muhammad Adi, Suganda, Venus \& Susanto, Eko Harry (2018). Dinamika Perusahaan Periklanan Indonesia: Studi Kasus Komunikasi dan Budaya Organisasi Dwi Sapta IMC dan Fortune Indonesia. Disertasi Universitas Padjadjaran. Bandung: Universitas Padjajaran.

Rakhmat, Jalaluddin, 2007. Metode Penelitian Komunikasi. Bandung: PT.Remaja Rosdakarya

Richard West, Lynn H.Turner. (2008). Pengantar Teori Komunikasi: Analisis dan Aplikasi (Buku 1) (Edisi 3). Jakarta: Salemba Humanika

Shinta Fransiska. (2019, November 28). Wawancara Pribadi.

Totok. (2019, November 28). Wawancara Pribadi

Yin, Robert K. (2013). “Studi Kasus”(Desain dan Metode), Jakarta : PT Raja Grafindo. 